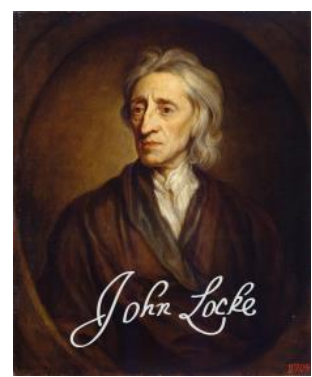

LOCKE STUDIES

Vol. 14

https://doi.org/10.5206/ls.2014.705 | ISSN: 1476-0290

Originally published: 2014

Published online: 19 FEBRUARY 2018

(C) Locke Studies, 2014

\title{
Some Possible Corruptions in the Text of Locke's Essay
}

\author{
J. R. MILTON (KING'S COLLEGE LONDON)
}

Recommended citation:

Milton, J. R. "Some Possible Corruptions in the Text of Locke's Essay." Locke Studies 14 (2014): 17-28.

https://doi.org/10.5206/ls.2014.705

For more information about this article:

https://ojs.lib.uwo.ca/index.php/locke/article/view/705

Locke Studies is published by The John Locke Society.

This is an open access article published under the terms of the Creative Commons Attribution-

NonCommercial-ShareAlike 4.0 International license, which permits use, distribution and reproduction in any medium, provided the original work is properly cited and shared under the original license. 


\title{
SOME POSSIBLE CORRUPTIONS IN THE TEXT OF LOCKE'S ESSAY
}

\author{
J. R. MILTON
}

The Essay concerning Human Understanding went through no fewer than four editions in Locke's lifetime, with another that incorporated some further input from him published in 1706, two years after his death. It might, therefore, seem reasonable to suppose that although printing errors undoubtedly occurred in the earlier editions (especially the first), by the time the fifth edition was published all of them would have been located and corrected. In his edition of the Essay, ${ }^{1}$ Peter Nidditch made rather more than twenty editorial changes, but all of them are very minor: most involve alteration of punctuation or capitalisation, and the only one that introduces a substantive change is the alteration of the plural 'Ideas' to the singular 'Idea' in II. xvi. 3 (205.20; all the references in this form given below are to the page- and line-numbers in Nidditch's edition).

In his edition Nidditch made no reference to the text of any of the earlier drafts of the Essay, though he subsequently prepared texts of Drafts A and B (1671), ${ }^{2}$ and began work on Draft C (1685). It turns out, however, that when the text of the published Essay is compared with these drafts, it is not difficult to find readings in them that at least suggest-and sometimes make it virtually certain - that the text found in all the editions of the Essay is corrupt and needs to be emended. (There are, of course, many more places where the readings in the earlier drafts are merely different from those in the Essay: these are not discussed here.)

\footnotetext{
1 John Locke, An Essay concerning Human Understanding, ed. P. H. Nidditch (Oxford, 1975).

2 Draft A of Locke's Essay Concerning Human Understanding (Sheffield, 1980), Draft B of Locke's Essay Concerning Human Understanding (Sheffield, 1982).
} 
When discussing the differences between the readings in Draft B, Draft C and the Essay (Draft A is generally too dissimilar to the Essay for it to be of much relevance), one major difference between the two drafts needs to be borne in mind. The manuscript of Draft B (Bodleian Library, MS Locke f. 26) is in Locke's hand throughout, and though there are a few places where the text is defective owing to carelessness on Locke's part, there is nothing that can be described as a copying error. The manuscript of Draft $\mathrm{C}$ (Pierpont Morgan Library, New York, MA 998) is a copy of Books I and II in the hand of Locke's manservant, Sylvester Brounower, and though there are frequent corrections and additions in Locke's hand, the great majority of the text was written by Brounower. Brounower would have made his copy from an earlier manuscript (probably but not certainly in Locke's hand) that is now lost. In the course of writing it he made numerous mistakes, and though Locke spotted and corrected most of them, it is clear that some escaped his notice. In those places where the text of the Essay differs from that in Draft $\mathrm{C}$, it needs to be considered whether the difference was caused by a copying error in the Draft, a printing error in the Essay, or a deliberate revision made by Locke. Only the second of these are relevant to the present enquiry.

\section{I}

It is convenient to begin with those places where the reading in all the editions of the Essay differs from that found in both the Drafts. The most interesting of these all occur in Book I:

1. In I. ii. 27 (64.4-9) we find the following passage directed against those who suppose that children are born with an innate knowledge of general maxims:

It might very well be expected, that these Principles should be perfectly known to Naturals; which being stamped immediately on the Soul (as these Men suppose) can have no dependence on the Constitutions, or Organs of the Body, the only confessed difference between them and others. 
There is nothing manifestly wrong with this, but in place of the phrase underlined here, Draft $\mathrm{C}$ has 'the Constitutions of the organs of the body' (I. ii. 14), and Draft B has 'the constitution of the organs of the body' $(\$ 13,122.7){ }^{3}$ There can be little dispute that the reading of Draft $\mathrm{B}$ is best, and it would seem likely that the plural 'Constitutions' in Draft $\mathrm{C}$ is a copying error, with the reading in the Essay a rather unsatisfactory correction of this.

2. In Essay I. iii. 24 (82.25-8) Locke stated that everyone relies on 'reverenced Propositions' on which they ground their reasoning:

which some, wanting skill and leisure, and others the inclination, and some being taught, that they ought not, to examine; there are few to be found, who are not exposed by their Ignorance, Laziness, Education, or Precipitancy, to take them upon trust.

Here all the editions of the Essay have 'exposed', while both Draft B $(\$ 10,116.23)$ and Draft $C$ have 'disposd'. In this case the reading of the Drafts is clearly much superior: 'exposed' is much more likely to be an uncorrected copying or printing error than a (thoroughly deleterious) change made by Locke. ${ }^{4}$

3. In the following section (I. iii. 25) the Essay (83.5-8) Locke asks the rhetorical question:

And where is the Man to be found, that can patiently prepare himself to bear the name of Whimsical, Sceptical, or Atheist, which he is sure to meet with, who does in the least scruple any of the common Opinions?

${ }^{3}$ No complete edition of Draft $\mathrm{C}$ has yet been published, and references are to the manuscript in the Pierpont Morgan Library. Page and line numbers in references to Draft B are to P. H. Nidditch and G. A. J. Rogers (eds), Drafts for the Essay concerning Human Understanding and Other Philosophical Writings (Oxford, 1990).

4 There is also a minor difference between the early editions of the Essay in the first part of the passage: the second and later editions have the text given here, while the first edition has 'taught. They', and Draft C (I. iii. 21) has 'taught they' without any punctuation. 
There is nothing obviously wrong with this, but both Draft B, $\S 10$ (117.10) and Draft C, I. iii. 22 have "whimsicall Sceptick or Atheist', which would seem preferable both grammatically and in terms of content.

4. In the following chapter (I. iv. 15, 93.15-17) Locke suggested that even if an idea of God were universally present in all mankind-something that Locke did not think had been established - this would prove rather less than who claimed it were apt to suppose:

And this universality of consent, so much argued, if it prove any native impressions, 'twill be only this: That God imprinted on the minds of all Men, speaking the same Language, a Name for Himself, but not any Idea...

Draft B $(\S 5,108.9)$ and Draft C (I. iv. 14) both have 'urged' instead of 'argued', and this is clearly a better word in this context. It should perhaps be mentioned that in a succession of editions of the Essay printed in the middle of the eighteenth century, from the eleventh edition (1735) onwards, 'argued' was replaced by 'urged'. Whether this was a deliberate alteration or an unconscious correction cannot now be determined, but it did not in the end become part of the accepted text: I have not noticed it in any edition of the Essay printed after 1800.

5. In the next paragraph (I. iv. 16,94.12-16) the editions of the Essay published in Locke's lifetime contain a defective text that was altered soon after his death, but not in a way that brought it back to the reading in Drafts B and C. The text in the first five editions is:

This was evidently the case of all Gentilism: Nor hath even amongst Jews, Christians, and Mahometans, who acknowledge but One God, this Doctrine, and the care is taken in those Nations to teach Men, to have true Notions of a GOD, prevailed so far, as to make Men to have the same, and true Ideas of Him.

This is manifestly ungrammatical, and in the first edition of The Works of John Locke (1714) the word 'is' in the portion underlined 
was omitted, so that the passage referred to "the care taken in those Nations'; this change was generally adopted, becoming part of the textus receptus of the Essay. In both Draft B $(\$ 5,108.29)$ and Draft C (I. iv. 16), however, the phrase read 'the care that is taken in those countrys', and it would seem that the defective text in the early editions should have been emended in this way, rather than in the way it was actually done.

6. There are two places in Book II where Drafts B and C agree in having a reading that looks better than the one in the Essay, though in neither case is the difference particularly important. The first occurs in the chapter 'Of Relation' (Essay, II. xxv. 8, 322.324):

Comparing two Men, in reference to one common Parent, it is very easy to frame the Ideas of Brothers, without having yet the perfect Idea of a Man.

Draft B ( $\$ 99,220.26-8)$ has 'Idea of Brothers', while Draft C (II. xxix. 10) originally had 'Ideas of Brothers'-like the Essay - before the final ' $\mathrm{s}$ ' in 'Ideas' was deleted. The singular is certainly better than the plural here, and indeed the text was adjusted accordingly in the 1828 edition.

7. In the chapter 'Of other Relations' (II. xxviii. 1, 349.4-6) Locke gives a classification of the different kinds of relation. The first are those that are capable of degrees, such as whiter, sweeter, bigger, etc.

These Relations depending on the Equality and Excess of the same simple Idea, in several Subjects, may be called, if one will, Proportional...

In both Draft B $(\S 147,261.7)$ and Draft C (II. xxxi. 2) the underlined phrase appears as 'Equality or Excesse' (without capitals in Draft B), which would seem much better: two things can be equally white, or one can be whiter than the other, but these are clearly alternatives, as the word 'or' in the Drafts indicates. 


\section{II}

Sometimes the text printed in the Essay is obscure or ungrammatical, and a comparison with the earlier drafts reveals that something had been left out, presumably by accident rather than deliberately.

8. In the chapter 'Of Duration, and its simple Modes', the first three editions have (II. xiv. 12, 185.27-31):

So that to me it seems, that the constant and regular Succession of Ideas in a waking Man, is, as it were, the Measure and Standard of all other Succession, which if it either exceeds their pace, as where two sounds or pains, etc. take up in their Succession the Duration of but one Idea; or else where any Motion or Succession is so slow, as that it keeps not pace with the Ideas in our Minds...

Something is clearly wrong here, and in the fourth and fifth editions the underlined phrase was changed to 'Successions, whereof if any one either exceeds the pace of our Ideas', followed by a semicolon. This is certainly better, but it still doesn't sound entirely right. In Draft C (II. xvii. 12) the passage is somewhat longer, but it still reads rather oddly:

Soe that to me it seemes that the Ideas of a wakeing man doe in a Constant \& somewhat regular pace continually succeed one another. which Succession of theirs is as it were the measure \& standard of all other Succession which either Exceeds their pace i.e. where two sounds or pains or smells \&c take up in their Succession the duration of but one Idea or else where any motion or Succession is so slow as that it keeps not pace with the Ideas in our mindes...

It is only when one goes back to Draft $\mathrm{B}, \S 105(229.8-15)$ that the source of the problem is revealed. Here we find:

Soe that to me it seemes that the Ideas of a wakeing man doe in a constant regular pace continually succeed one an other, which succession of theirs is as it were the measure $\&$ standard of all other successions. For where ever any motion or other succession either exceeds their pace i e where two sounds or pains or smells \&c take up in their succession the duration of but 
one Idea, or else where any motion or succession is soe slow as that it keepe not pace with the Ideas in our mindes...

At some stage in the transmission of the text, a copyist-perhaps Locke himself, but probably Brounower-left out the passage between the two occurrences of the word 'succession' (or 'successions'). It is a classic example of the phenomenon textual critics refer to as homoioteleuton: the scribe copies the text in short chunks, preferably ones ending with a reasonably conspicuous word, but when he has finished writing the passage in the new manuscript, he inadvertently returns not to the place where he had left off, but to the same word (or a very similar word) occurring later in the same line, or somewhere in the next few lines.

9. Another omission occurs later in the same chapter $(\S 30$, 195.16-22). The last part of this reads:

And by the same way of adding Minutes, Hours, or Years, (i.e. such or such parts of the Sun's revolution, or any other period whereof I have the Idea,) proceed in infinitum, and suppose a duration exceeding as many such periods as I can reckon, let me add whilst I will, which I think is the notion we have of Eternity, of whose infinity we have no other notion, than we have of the infinity of Number, to which we can add for ever without end.

The general drift of this is clear enough, but the wording is perhaps a little clumsy. The equivalent passage in Draft C (II. xvii. 57) is the same (except for accidentals) as in the Essay, but in Draft B $(\S 123,247.23-30)$ the last part, on our idea of eternity, is noticeably longer:

Of whose infinitie we have noe other notion then we have of the infinitie of number, which is not the notion of an actuall positive thing but such as to which we can adde for ever without end.

The part underlined is missing from the later versions. This also appears to be a case of homoioteleuton, the repeated word being 'which'. 


\section{III}

In all the cases discussed above there are parallel passages in both the earlier drafts, but there are other passages in the Essay that have no equivalent in Draft B, but where Draft $\mathrm{C}$ appears to have a better text.

10. In the account of primary and secondary qualities Locke gave an explanation of why the same water can simultaneously feel hot to one hand and cold to the other (II. viii. 21, 139.35-40):

if a Body be applied to the two Hands, which has in its minute Particles a greater motion, than in those of one of the Hands, and a less, than in those of the other, it will increase the motion of the one Hand, and lessen it in the other, and so cause the different Sensations of Heat and Cold, that depend thereon.

In Draft C, II. vii. 23, the passage is almost exactly the same (apart from accidentals), but the words 'of the one Hand' in the Essay appear as 'in one hand' in the Draft. The latter reading is manifestly superior: not only is the balance of the passage restored, with a comparison between what is happening in one hand and in the other, but it also makes much better philosophical sense: it is the motion of the particles in the hand that is greater, not the motion of the hand itself.

11. Another difference can be found on the chapter 'Of Number', where the Essay has (II. xvi. 5, 206.22-5):

All Numeration being but still the adding of one Unite more, and giving to the whole together, as comprehended in one Idea, a new or distinct Name or Sign, whereby to know it from those before and after...

In Draft C (II. xix. 6), there is ' $\&$ ' in place of 'or'; this would seem better, since there is no obvious reason to make a disjunction between a new and a distinct name.

12. In the chapter 'Of Infinity' the Essay has (II. xvii. 15, 217.34-35): 
The Idea of Infinite, has, I confess, something of positive in all those things we apply to it.

Draft C (II. xx. 15) gives the last two words as 'it to', which again seems preferable: it makes more sense to suppose that ideas are applied to things, than things to ideas.

13. Near the beginning of the chapter on power (Essay, II. xxi. 2, 234.6-10) Locke raised the question

Whether Matter be not wholly destitute of active Power, as its Author GOD is truly above all passive Power; and whether the intermediate state of created Spirits be not that alone, which is capable of both active and passive Power, may be worth consideration.

In Draft C (II. xxv. 3) the passage is almost identical, except that instead of 'truly' there is the word 'wholy'. The version in the Draft is arguably better, in that it makes it clear that the contrast is between Matter as wholly lacking in any active power and God as wholly free from any passive power. One reason for taking seriously the possibility that it might be the more authentic reading is that in the manuscript of Draft $\mathrm{C}$ this sentence occurs in part of a long insertion in Locke's hand, so that here at least there is no possibility of a scribal error having been made by Brounower.

14. In the chapter on substance Locke remarked that though the postulation of an aether may explain the coherence of larger bodies, it cannot explain the internal coherence of the particles of which the aether is itself made (Essay, II. xxiii. 23, 308.29-33):

and by how much the more evident it proves, that the parts of other Bodies are held together, by the external pressure of the Æther...by so much the more it leaves us in the dark, concerning the cohesion of the parts of the Corpuscles of the Æther it self...

The passage was taken over from Draft C (II. xxvii. 22), but here it begins ' $\&$ by how much the more evidently it proves'. The reading in the Draft is manifestly superior. The word was changed from 'evident' to 'evidently' in two mid-eighteenth 
century editions of the Essay (London, 1760; Edinburgh, 1765), but it did not become part of the received text.

\section{IV}

There are two places where the re-introduction of a word or phrase in Draft C makes a passage in the Essay more intelligible.

15. The first is in the chapter on substance (Essay, II. xxiii. 27, 311.9-12):

So far is our Extension of Body, (which is nothing but the cohesion of solid parts,) from being clearer, or more distinct, when we would enquire into the Nature, Cause, or Manner of it, than the Idea of Thinking.

In Draft C (II. xxvii. 22) the words 'Idea of' occur before 'Extension of Body'. This is surely correct: it makes no sense to talk about 'our extension of body', or to describe the extension of body as being clearer or more distinct: the aim of the passage was to draw a contrast between the idea of the extension of body and the idea of thinking, not between the extension of body and the idea of thinking.

16. The second is in the chapter 'Of Real and Fantastical Ideas'. In II. xxx. 4 (373.26-30) the Essay has:

Mixed Modes and Relations, having no other reality, but what they have in the Minds of Men, there is nothing more required to those kind of Ideas, to make them real, but that they be so framed, that there be a possibility of existing conformable to them.

In Draft C (II. xxxiii. 4) the part underlined here appears as 'a possibility of things existing'. The reading in the Essay is by no means absurd, but that in the Draft would seem considerably better. 
Finally there are two places-both in Book I-where Draft C agrees with the Essay in a reading that looks problematic, but Draft $\mathrm{B}$ has something better.

17. The first of these is to be found at the start of I. ii. 28 (64.3565.1):

I know not how absurd this may seem to the Masters of Demonstration: And probably, it will hardly down with any Body at first Hearing.

The passage is the same, apart from accidentals, in Draft C (I. ii. $22)$, but its precursor in Draft $B(\$ 11,119.8-10)$ is rather different:

These two reasons I doubt not but will seeme great absurditys to the masters of demonstration, \& will not easily goe downe at first heareing with almost any one...

The word 'down' can be used as a verb in English - as in the expression 'down tools' - but in all the uses recorded in the $O E D$ the verb is transitive, and in none of them is it used in anything like the way it is here. 'Go down' makes far more sense, ${ }^{5}$ and in A. C. Fraser's edition of 1894 the passage was altered accordingly.

18. Another example occurs in Essay, I. iii. 22 (81.19-26):

This, however strange it may seem, is that which every days Experience confirms; and will not, perhaps, appear so wonderful, if we consider the ways, and steps by which it is brought about; and how really it may come to pass, that Doctrines, that have been derived from no better original, than the Superstition of a Nurse, or the Authority of an old Woman; may, by length of time, and consent of Neighbours, grow up to the dignity of Principles in Religion or Morality.

5 Compare Essay, IV. xx. 10 (712.36-38): 'whereas the grossest Absurdities and Improbabilities, being but agreeable to such Principles, go down glibly, and are easily digested'. 
The word 'really' also appears (spelt as 'realy') in the equivalent passage in Draft C (I. iii. 19), but in Draft B, where the entire passage can be found with only minor differences $(\$ 9,115.13-20)$, the corresponding word is 'naturaly', a reading that makes much more sense. It should be noted that when written the difference between the two words could be quite small: 'naturally' was often abbreviated in manuscript as 'nāāly', as it was in the manuscript of Draft B, ${ }^{6}$ and a copyist could easily have mis-read this as 'realy'.

King's College London

${ }^{6}$ Bodl., MS Locke f. 26, p. 23. 